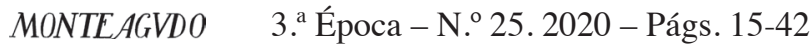

\title{
Las Caricaturas literarias de Galdós
}

\author{
Mariano Baquero Goyanes \\ Universidad de Murcia
}

\section{RESUMEN:}

Benito Pérez Galdós poseía un talento excepcional para la caracterización de sus personajes. Destacan en su obra las descripciones caricaturescas. En este estudio se analizan las influencias que convergen en algunas de estas descripciones y la razón por la que Galdós incluye en novelas de índole e intención realista descripciones hiperbólicas y caricaturescas cercanas a lo irreal. Se concluye que son reflejo de la fusión habitual en su narrativa entre lo mágico-alegórico y lo documental-realista, entre el sueño alucinante y la observación cotidiana.

PALABRAS CLAVE:

Pérez Galdós, caricatura, realismo, alegoría, vida cotidiana, sueño, alucinación.

\begin{abstract}
:
Benito Pérez Galdós had an exceptional talent for characterizing his characters. The caricaturesque descriptions stand out in his work. This paper analyzes the influences that converge in some of these descriptions and the reason why Galdós includes hyperbolic and caricatural descriptions close to the unreal in novels of a realistic nature and intention. It is concluded that these descriptions are reflect the usual fusion in his narrative between the magical-allegorical and the documentary-realistic, between the amazing dream and the daily observation.
\end{abstract}

\section{KEYWORDS:}

Pérez Galdós, cartoon, realism, allegory, daily life, dream, hallucination.

Ponderar el talento, el arte excepcional de Galdós en la caracterización de sus personajes novelescos, equivaldría a repetir una verdad de todos conocida. Puede, en cambio, que ofrezca cierto interés hacer ver las distintas influencias que convergieron en algunas de esas descripciones, concretamente en las de índole caricaturesca. Y aún más importante que el rastreo de tales influencias resultaría el explicar por qué Galdós, en novelas de textura e intención realistas, incluye descripciones tan hiperbólicas y caricaturescas que inciden en lo irreal y que sirven para acentuar el vaivén y fusión que en toda la obra galdosiana suele darse, entre lo mágico-alegórico y lo documental-realista, entre el sueño alucinante y la observación cotidiana. 
Fue el propio Galdós el que, en una de sus primeras novelas, El audaz (1871), aludió al gusto por la caricatura como propio del siglo XVIII y de los comienzos del suyo:

El último tercio del siglo XVIII y los primeros años del presente fueron la época de las caricaturas. La de don Juan no había de faltar en aquella sociedad, que Goya y don Ramón de la Cruz retrataron fielmente y con mano maestra. ${ }^{1}$

Obsérvese que para Galdós no hay contradicción entre el retratar fielmente y el hacerlo caricaturescamente. La exactitud en la transcripción del rasgo fisiognómico del ser retratado, no sólo no es incompatible con la caricaturización del mismo - es decir, su abultamiento, su desfiguración, su enfatización -, sino que, por el contrario, queda acrecida con tal procedimiento. Para Galdós la caricatura no es antirrealista, ya que su empleo permite lograr la fidelidad en el retrato, conseguible no tanto con la exacta transcripción del detalle físico, como con su interpretación, es decir, con su sometimiento al arte subjetivo del pintor. ${ }^{2}$

No se crea que ésta es una opinión juvenil de Galdós, rectificada más tarde, a compás de los acontecimientos histórico-literarios, es decir, del progresivo éxito de la fórmula naturalista, de la sujeción a lo escuetamente fotográfico, sin interposición,

\footnotetext{
${ }^{1}$ Benito Pérez Galdós, Obras Completas, Ed. Aguilar, Madrid, 1951, IV, pág. 242b. Prescindo en estas páginas de una teoría general de la caricatura. El lector interesado en lo que a la misma se refiere -y en especial a la caricatura específicamente literaria- puede consultar, entre otras obras, la de Wolfgang Kayser, Das Groteske, Gerhard Stelling Verlag, Oldenbourg, 1957, especialmente el capítulo Das Groteske im 19. Jahrhundert (Pág. 108 y ss.).

${ }^{2}$ A este respecto recuérdese lo que W. M. Urban dice: «La verdadera naturaleza del fenómeno de deformación se señala claramente en una carta de Van Gogh. "Di a Seurat -escribe- que yo estaría perdido si mis figuras fueran correctas. Dile que si toma una fotografía de un hombre cavando, en mi opinión, él tiene la seguridad de verlo como si no estuviera haciendo eso. Dile que creo que las figuras de Miguel Ángel son magníficas, aun cuando, ciertamente, las piernas son demasiado largas y los huesos de la pelvis y de la cadera son demasiado anchos... Dile que es mi más ferviente deseo saber cómo se pueden realizar esas desviaciones de la realidad (subrayamos nosotros), esas inexactitudes y transfiguraciones que suceden por acaso. Bien, si tú quieres, son mentiras, pero son más valiosas que los valores reales". La deformación es, pues, una desviación de lo real en el sentido de copia literal de lo real.

Como tales, estas desviaciones son mentiras, si se quiere. El elemento de ficción está presente y se reconoce como ficticio. Pero estas desviaciones, estas mentiras, son más valiosas que los valores reales. Esta última frase es la que especialmente exige nuestra atención, y contiene toda la esencia del símbolo estético. ¿Qué significa aquí, pues, la palabra valioso? Para Van Gogh quiere decir -y lo mismo para todo artista- que precisamente por estas desviaciones se aprehenden y expresan ciertos aspectos de la realidad que no podrían mostrarse de otra manera» (Wilbur Marshall Urban, Lenguaje y realidad, trad. de Carlos Villegas y Jorge Portilla, Méjico, 1952, págs. 390-391).
} 
en lo posible, de la mirada interpretadora y configuradora. La verdad es que en 1901, y en el prólogo que Galdós escribe para la tercera edición de La Regenta, de Clarín, cabe advertir opiniones semejantes, trasladadas ya a un plano de específica técnica novelesca, y, por lo tanto, de mayor interés aún que las suscitadas por el arte retratista y caricaturesco de Goya y de don Ramón de la Cruz. En tal prólogo, Galdós, al hablar de los orígenes españoles del naturalismo - rastreables en nuestra picaresca, en el arte cervantino, etc.- , considera que tal corriente literaria, en su regreso al solar patrio, ha vuelto radicalmente desfigurada, por obra y gracia, sobre todo, del humour inglés: Fielding, Dickens, Thackeray. Más intenso aún es el cambio sufrido por el añejo realismo español al pasar por Francia:

Lo que perdió en gracia y donosura, lo ganó en fuerza analítica y en extensión, aplicándose a estados psicológicos que no encajan fácilmente en la forma picaresca. ${ }^{3}$

Parece como si Galdós prefiriera el naturalismo a la manera inglesa - es decir, transformada la socarronería española en humour-, al naturalismo francés. El de Fielding o Dickens está más próximo al cervantino español, por tener en él su origen. Y concluye Galdós:

Pero, al fin, consolémonos de nuestro aislamiento en el rincón occidental, reconociendo en familia que nuestro arte de la naturalidad, con su feliz concierto entre lo serio y lo cómico, responde mejor que el francés a la verdad humana; que las crudezas descriptivas pierden toda repugnancia bajo la máscara burlesca empleada por Quevedo. ${ }^{4}$

El interés de las líneas que hemos transcrito es grande con relación al tema que hoy nos ocupa. Por una parte, Galdós no oculta sus bien conocidas preferencias por la novelística inglesa - hecho importante a la hora de considerar la influencia de Dickens en el arte de la caricatura galdosiana-, y por otra, el escritor nos informa de su admiración por el arte descriptivo de Quevedo, como manifestación feliz de realismo que, pese a sus crudezas, no resulta repugnante al quedar desfigurado bajo una máscara burlesca.

Creo que es legítimo conectar este texto con el antes recordado de El audaz, pues ambos participan del mismo sentido e intención: para Galdós cabe un arte descriptivo, muy hispánico, en el que realismo y deformación caricaturesca se amalgaman perfectamente, y en el que la exactitud y veracidad en el retrato no sólo no sufren merma por la presencia del toque o toques caricaturescos, sino que, al revés, quedan

${ }^{3}$ Galdós, O.C., ed. cit., tomo VI, pág. 1.448a.

${ }^{4} \mathrm{Id}$. 
por ellos reforzadas en una dimensión más importante que la estrictamente fotográfica, al servirse del arte interpretativo y al dar al lector algo más que el dato escueto.

El que Galdós apoye su teoría, ahora, en el ejemplo de Quevedo - como antes en los de Goya y don Ramón de la Cruz - ilumina, desde este plano crítico, un amplio sector de las caricaturas literarias galdosianas, con su raíz o arranque en el arte quevedesco. Pero - insisto - más importante aún que esta, por otra parte, bien conocida derivación, resulta el que el autor de los Episodios no vea contradicción entre realismo y máscara burlesca, entre fidelidad en la transcripción de unos rasgos y su deliberada deformación caricaturesca. Galdós considera el arte de Quevedo realista y hasta crudo, lo cual no supone una postura original, personal, ya que, en cierto modo, tal ha solido ser la postura de la crítica tradicional, empeñada en la sola valoración de nuestra literatura como arte realista, olvidada o mal entendida esa otra faz, idealista, ilusionista, de la misma a la que Dámaso Alonso se refirió en un ensayo-clave y que hoy resulta imprescindible para un recto entendimiento, no sólo de la expresión literaria española, sino hasta de nuestra manera de ser como colectividad nacional.

Lo que aquí importa subrayar es que el encuadramiento del arte descriptivo quevedesco, como arte realista a la manera hispánica, se convierte en justificación y poco menos que en razón de ser del arte descriptivo galdosiano, hecho de realismo y desmesura, de concreción e hipérbole, de exactitud y de fábula.

He de prescindir aquí de aspectos estudiados ya en el arte galdosiano, como los referentes a su gusto por el símbolo y la alegoría-magistralmente tratados por Joaquín Casalduero - o los conectados con la atención prestada al mundo de los sueños, las alucinaciones, las neurosis - certeramente analizados por Carlos Clavería - . Si traigo ahora al recuerdo del lector tales aspectos de la obra galdosiana, así como lo que en ésta hay de cruce, pugna y fusión de romanticismo con sátira antirromántica y minuciosidad naturalista, lo hago movido del deseo de establecer una relación entre todos esos rasgos, tan complejos, y la dualidad a que ahora estoy refiriéndome, que, así entendida y situada, viene a ser, en escala reducida, una versión más del oscilar galdosiano entre lo rigurosamente histórico y lo alucinadamente onírico, entre realidad y magia, entre el dato y la alegoría. La caricatura hiperbólica, antirrealista en su literalidad, realista en su más hondo sentido, vendría a constituir un campo de experimentación capaz de permitirnos observar, en sus reducidos confines, la misma intensa oscilación y dualidad que es característica del arte galdosiano contemplado en su totalidad y como a vista de pájaro. Desde tan empinada perspectiva son tantos y tan ricos los contrastes percibidos, que el conjunto posee la animación, el claroscuro y el movimiento propios de la vida. Examinada la misma obra desde la reducidísima perspectiva de un solo aspecto técnico, la descripción caricaturesca, comprendemos 
entonces la relación y trabazón existentes entre el conjunto y el detalle, como si en éste repercutiera, en mínima escala, lo que en aquél tiene la abultada fuerza de lo ostentosamente perceptible.

Y si somos capaces de perseguir el sesgo de tal recurso técnico a lo largo de toda la obra galdosiana y de comprobar su existencia, en mayor o menor proporción, con distintos matices, pero nunca extinguida, desde las obras juveniles a las de madurez y vejez, podríamos comprender cómo el Galdós que inicia su carrera literaria con los símbolos y los sueños de La Fontana de Oro y La Sombra (1870), regresa en la vejez al punto de partida con las alegorías de Amadeo I (1910), Cánovas (1912) y la magia de El caballero encantado (1904).

Entre unas y otras novelas, Galdós ha escrito muchos y muy variados relatos, abarcando muchos temas y manejando plurales técnicas. Pero a la hora de describir ciertos personajes, Galdós se ha servido siempre, en todas sus épocas, de los recursos cómicos y caricaturescos que le facilitaba su concepción del realismo a la española y que, a la vez, le ofrecían, como imitación o incitación, algunos de sus escritores predilectos. Estudiar este punto detalladamente es algo a que, por ahora, he de renunciar. No quiero, sin embargo, dejar de apuntar algunas líneas generales que, aun sin pretensiones de novedad, servirán para encuadrar más firmemente mi interpretación de la caricatura galdosiana como consecuencia de su concepción y teoría del realismo descriptivo.

Entre esos autores predilectos a que acabo de aludir, hay uno tan próximo a Galdós en tantos aspectos, que conviene recordarlo en primer lugar: Mesonero Romanos, elogiado en diversas ocasiones, presentado en Los Apostólicos (1879) como el resucitador de «la casi olvidada pintura de la realidad y de la vida española tal como la practicó Cervantes», como el creador de «el cuadro de costumbres, la sátira amena, la rica pintura de la vida, elementos de que toma su sustancia y hechura la novela».5 Tales artículos de Mesonero Romanos fueron utilizados como rica cantera informativa a la hora de escribir los Episodios Nacionales. E incluso el gusto galdosiano por pasar personajes de unas novelas a otras, su complacencia en tales reapariciones, tiene algún antecedente en los artículos de Mesonero. Recuérdese cómo el Pascual Bailón Corredera de Los cómicos en Cuaresma reaparece en La capa vieja y el baile de candil, de manera semejante a como D. Homobono Quiñones es protagonista de los cuadros El día 30 de mes y El cesante. No hace falta decir que tales reapariciones tienen un sentido y alcance muy distinto en Mesonero y en Galdós, próximo este último a Balzac en el manejo de tal recurso y en su función vivificadora y realista, dentro de un mundo novelesco de extraordinaria amplitud y concebido cíclicamente. Pero aunque así sea, la coincidencia resulta curiosa, sumada a la devoción del autor

${ }^{5} I d$. , tomo II, pág. $190 b$. 
de Miau por su gran precursor en el conocimiento, goce y descripción de Madrid, $E l$ Curioso Parlante.

Fue éste moderadamente aficionado a la caricatura, conseguida más por el diálogo, la acción y la ingenua comicidad onomástica que por el pormenor descriptivo. Pero algún caso hay en que la importancia concedida por el articulista a un rostro o un atuendo le lleva a la minuciosidad caricaturesca. El más conocido ejemplo es el retrato de aquel imaginado sobrino que aparece en El Romanticismo y los románticos:

Quedó, pues, reducido todo el atavío de su persona a un estrecho pantalón que designaba la musculatura pronunciada de aquellas piernas; una levitilla de menguada faldamenta, y abrochada tenazmente hasta la nuez de la garganta; un pañuelo negro descuidadamente añudado en torno de ésta, y un sombrero de misteriosa forma, fuertemente introducido hasta la ceja izquierda. Por bajo de él, descolgábanse de entrambos lados de la cabeza dos guedejas de pelo negro y barnizado, que, formando un bucle convexo, se introducían por bajo de las orejas, haciendo desaparecer éstas de la vista del espectador; las patillas, la barba y el bigote, formando una continuación de aquella espesura daban con dificultad permiso para blanquear a dos mejillas lívidas, dos labios mortecinos, una afilada nariz, dos ojos grandes, negros y de mirar sombrío; una frente triangular y fatídica. Tal era la vera efigies de mi sobrino, y no hay que decir que tan uniforme tristura ofrecía no sé qué de siniestro e inanimado, de suerte que no pocas veces, cuando cruzado de brazos y la barba sumida en el pecho, se hallaba abismado en sus tétricas reflexiones, llegaba yo a dudar de si era él mismo o sólo su traje colgado de una percha; y acontecióme más de una ocasión el ir a hablarle por la espalda, creyendo verle de frente, o darle una palmada en el pecho, juzgando dársela en el lomo.

Los hiperbólicos trazos que rematan esta caricaturesca descripción se corresponden, en su tono, con el resto del artículo, en el que Mesonero Romanos ofrece una parodia de los tópicos románticos. En tal ajuste de tono reside la diferencia fundamental entre una caricatura como ésta y las tan frecuentes en las novelas galdosianas, cuya tonalidad, mantenida página tras página, nada tiene que ver, en conjunto, con la índole satírica y deliberadamente desorbitada del costumbrismo, género en el que el malicioso abultamiento de rasgos es poco menos que necesario, dada su intención o finalidad.

Por el contrario, algunas caricaturas galdosianas - e incluso dickensianas - parecen, a primera vista, despegarse del conjunto: tan diferente es la tónica realista de éste de la deformación hiperbólica de aquéllas. 
Pero antes de insistir en este punto - para cuya comprensión me permito recordar al lector lo antes expuesto sobre la particular concepción de Galdós acerca del realismo more hispanico, hecho de crudeza y de máscara-, me interesa destacar ahora un rasgo en el que alguna vez coincide el autor de los Episodios con El Curioso Parlante como caricaturista literario.

Se habrá observado en el retrato del joven romántico que el máximo efecto cómico radica en la hiperbólica cosificación de un ser humano, reducido, por virtud de su artificioso aspecto y vestimenta, a un «no sé qué de siniestro e inanimado», que permite a Mesonero la comparación con la percha o la confusión de pecho y espalda.

En Dickens se encuentran alguna vez caricaturas semejantes en lo que a cosificación de un ser humano se refiere. Recuérdese aquella escena del capítulo V de David Copperfield (1849-50), en que el maestro de Salem House saluda a una anciana:

- ¿Cómo se encuentra hoy la señora Fibbitson? - dijo el maestro, mirando a otra anciana que estaba sentada junto al fuego en un amplio sillón y que producía el efecto de ser un puro montón de ropas, hasta el punto de que aun hoy día estoy satisfecho de no haberme sentado por equivocación encima de ella. ${ }^{6}$

La cosificación dickensiana alcanza a veces el grado hiperbólico que supone la vivificación de lo inanimado. Se trata de un procedimiento reversible: en principio, el escritor compara a un ser humano con algo inanimado, y después, una vez que con tal comparación ha cosificado al sujeto, vivifica al ser cosificado para así reforzar o acrecentar el efecto cómico. Véase este pasaje de La Pequeña Dorrit (1857):

El señor Merdle dio el brazo para bajar al comedor a una condesa que se hallaba recluida Dios sabe dónde en lo más profundo de un vestido inmenso, con el que ella guardaba la proporción que guarda el cogollo con el repollo crecido y completo. Si se me admite este símil tan bajo, el vestido descendía por las escaleras lo mismo que un riquísimo prado de seda brochada, sin que nadie se diese cuenta de lo pequeñísima que era la persona que lo arrastraba. $^{7}$

Se observará en los dos ejemplos dickensianos transcritos, y sobre todo en este último, una irónica compostura, muy victoriana, que lleva al escritor a plantear la hiperbólica comparación en un plano racional y mesurado. He aquí una diferencia fundamental entre el arte caricaturesco de Dickens $-\mathrm{y}$ en cierto modo también el

\footnotetext{
${ }^{6}$ Charles Dickens, Obras Completas, trad. de José M.a, Herrera, Ed. Aguilar, Madrid, 1952, tomo IV, pág. 68b.

${ }^{7} I d$., tomo VI, pág. $223 a$.
} 
de Galdós - y el de un Quevedo, por ejemplo. Para la fantasía barroca del autor de los Sueños no hay freno ni límite. Dickens y Galdós oscilan muchas veces entre el vértigo de la hipérbole y el lastre o atadura de lo racional-realista.

Véase cuan expresiva resulta, confrontada con las caricaturas hasta ahora transcritas, ésta de Galdós, perteneciente al capítulo III de Un faccioso más y algunos frailes menos (1879):

Doña María Salomé estaba tan momificada que parecía haber sido remitida en aquellos días del Egipto, y que la acababan de desembalar para exponerla a la curiosidad de los amantes de la etnografía. Fija en su silleta baja, que había llegado a ser parte de su persona, se ocupaba en arreglar perifollos para decorarse, y a su lado se veían, en diversas cestillas de mimbre, plumas apolilladas, cintas de matices mustios, trapos de seda arrugados y descoloridos como las hojas de otoño, todo impregnado de un cierto olor de tumba, mezclado de perfume de alcanfor. Decían malas lenguas que al hacerse ropa juntaba los pedazos y se los cosía con la misma piel; también decían que comía alcanfor y que estaba forrada con cabritilla. Boberías maliciosas son éstas, de que los historiadores serios no debemos hacer caso. ${ }^{8}$

Por varios motivos ofrece interés esta caricatura galdosiana, independientemente de su valor literario como tal. Por un lado, encontramos en ella el ya aludido proceso de cosificación de un ser humano, visto en Mesonero Romanos y en Dickens. Tal cosificación presenta en Galdós el mismo oscilante carácter del último ejemplo transcrito de Dickens, aunque expresado de otra manera. La deshumanización que, en el texto galdosiano, afecta a D. ${ }^{a}$ María Salomé de Porreño es fundamentalmente eso, una deshumanización, más que una plena cosificación. El viejo y manido término de comparación - una momia - no despoja totalmente a María Salomé de su condición humana, si bien, según avanza la descripción caricaturesca, los nuevos resortes cómicos que maneja el novelista acentúan el proceso de deshumanización al acercar hiperbólicamente a la dama a una silla o, por mejor decir, al fusionar centáuricamente - «su silleta baja, que había llegado a ser parte de su persona»- un ser animado y un objeto inanimado. El marco de trapos viejos y descoloridos, de plumas apolilladas y cintas mustias, acendra el perfil cosificado de Salomé, al establecer de nuevo Galdós otra cómica amalgama de ropa y piel. Pero el novelista procede como Dickens, es decir, con irónica compostura, expresada aquí a través del espejo deformador que es el chisme: «Decían malas lenguas...»; «También decían...». Quevedo hubiese dicho rotundamente que D. ${ }^{a}$ María Salomé comía alcanfor y que, en efecto, estaba forrada de cabritilla.

${ }^{8}$ Galdós, O.C., ed. cit., tomo II, págs. 219-220. 
Interesa también en esta caricatura galdosiana lo que pudiéramos considerar marco de la misma, es decir, todo ese grotesco atrezzo que rodea y define a María Salomé, que compone su verdadero perfil caricaturesco. Todo lo recogido en la descripción galdosiana participa de la misma condición añeja, descolorida y arrugada de la propia María Salomé. Ser humano y objetos — trapos, plumas, evocadas hojas de otoño, alcanfor - armonizan cómicamente, y más si tenemos en cuenta que el trozo transcrito es sólo eso, un trozo. La pintura total - una pintura de interior - se encuentra no en Un faccioso más, sino en La Fontana de Oro, donde por primera vez tuvo ocasión Galdós de ocuparse de las hermanas Porreño - trasunto de las mitológicas Arpías y casi, casi, por su resonancia sepulcral, de las Parcas-, situadas en el marco de su casa, minuciosamente descrito en el capítulo XV, titulado significativamente Las tres ruinas. Recomiendo al lector la lectura completa de tal capítulo para mejor situar la descripción caricaturesca que posteriormente Galdós volvió a dar de María Salomé.

No fue ésta la única vez que Galdós se sirvió de un marco ambientador para una mejor y más caricaturesca descripción de un personaje. En Los Apostólicos (1879), y en el capítulo XVII, se ocupa el novelista de don Felicísimo Carnicero y de su casa. Ambas descripciones - la del hombre y la vivienda - están casi en la misma relación de interdependencia que la de las Porreño y su casa. Pero en tanto que en el retrato de María Salomé son los trapos, las sedas, las plumas - toda esa marchita y desvaída naturaleza muerta que la rodea - lo que rima con la momificada figura femenina hasta el punto de conferir a ésta la calidad de un trapo más, en el caso de D. Felicísimo es la figura humana la que, irradiando miseria y vejez, parece humanizar la casa en que vive, configurándola a su semejanza, convirtiéndola en poco menos que en expresivo y monstruoso apéndice de su personalidad.

La descripción de D. Felicísimo participa del mismo oscilante tono que hemos señalado en la de María Salomé y en las de Dickens. Contemplamos la cosificación relativa de un ser humano, relativa por intervenir en ella racionalmente el autor, deteniendo el vuelo a la desenfrenada hipérbole:

Hacia el promedio de la calle del Duque de Alba vivía el señor don Felicísimo Carnicero [...]. Era de edad muy avanzada, pero inapreciable, porque sus facciones habían tomado desde muy atrás un acartonamiento o petrificación que le ponía, sin que él lo sospechara, en los dominios de la paleontología. Su cara, donde la piel había tomado cierta consistencia y solidez calcárea, y donde las arrugas semejaban los hoyos y los cuarteados durísimos de un guijarro, era una de esas caras que no admiten la suposición de haber sido menos viejas en otra época. ${ }^{9}$

${ }^{9}$ Id., tomo II, pág. $149 \mathrm{~b}$. 
La dureza, la fosilización, la vejez sempiterna de don Felicísimo tienen su correlato en la estructura ruinosa de la casa en que vive:

Era de un solo piso alto, antiquísimo, y en invierno tenía condiciones inmejorables para que cuantos entraban en ella se hicieran cargo de cómo es la Siberia. Había sido edificada en los tiempos en que la calle del Duque de Alba se llamaba de la Emperatriz, y ya, en tan largos servicios, no podía disimular las ganas que tenía de reposarse en el suelo, soltando el peso del techo, estirándose de tabiques y paredes para sepultar su cornisa en el sótano y rascarse con las tejas de su cabeza los entumecidos pies de sus cimientos. Pero D. Felicísimo, que no consentía que su casa viviese menos que él, la apuntaló toda, y así, desde el portal se encontraban fuertes vigas que daban el quién vive. La escalera, que partía de menguados arcos de yeso, también tenía dos o tres muletas, y los escalones se echaban de un lado, como si quisieran dormir la siesta. Arriba, los pisos eran tales que una naranja tirada en ellos hubiera estado rodando una hora antes de encontrar sitio en que posarse, $\mathrm{y}$ por los pasillos era necesario ir con tiento, so pena de tropezar con algún poste que estaba de centinela como un suizo, con orden de no permitir que el techo se cayera mientras él estuviera allí. ${ }^{10}$

Fuera de alguna evidente hipérbole, como la del rodar de la naranja por el suelo, el resto de la descripción se mantiene en términos realistas, que sólo se concretan en caricaturescos por el mantenido proceso de humanización de que Galdós se sirve para describir la vivienda de D. Felicísimo, susceptible de ser alineada junto a otras conseguidísimas descripciones de este tipo en nuestra literatura novelesca, como la tan conocida y admirable de las casas y plaza porticada en Pilares que se encuentra en las primeras páginas de Tigre Juan, de Ramón Pérez de Ayala.

Galdós, arrastrado por su poder de invención caricaturesca, no se contenta con la humanizada descripción de la casa - exterior e interior - de D. Felicísimo, sino que prolonga la nota cómica e hiperbólica al pormenorizado recuento del mobiliario y enseres de tal vivienda, con rasgos tan quevedescos como el siguiente, comparable a los frecuentes y extremosos encarecimientos de que se sirve Quevedo para ponderar la vejez o antigüedad de un ser o un objeto:

Cuatro sillones de claveteado cuero, contemporáneos del cuadro de las Ánimas del Purgatorio, si no del Purgatorio mismo. ${ }^{11}$

\footnotetext{
${ }^{10} I d$., pág. 151.

${ }^{11} I d$., pág. $152 a$.
} 
Para rematar tan esperpéntica descripción y para enmarcar más enfáticamente aún la vejez, miseria y ruina de D. Felicísimo y de todo su contorno, Galdós humaniza con grotesco patetismo el despacho en que trabaja este personaje:

Detrás del sillón de la mesa había un largo estante del tamaño de la pared, cuyas puertas tenían, en vez de vidrios, rejillas de alambres, y por los huecos de éstas asomaban sus caras amarillentas los legajos, como enfermos que se asoman a las rejas de un hospital. Muchos tenían cruzados de cintas rojas y cartoncillos colgantes con rótulos. Algunos estaban tendidos horizontalmente, semejando no ya enfermos, sino verdaderos cadáveres que no volverían a la vida aunque les royesen ratones mil; otros estaban, inclinados sobre sus compañeros, como borrachos o malheridos, y los menos aparecían completamente erguidos y derechos. Éstos eran los que se asían a las rejillas, y aun echaban fuera sus cintas rojas cual si meditaran una evasión arriesgada. ${ }^{12}$

Es la suma de todos estos detalles la que da plena configuración caricaturesca a D. Felicísimo, personaje esperpéntico en cuya descripción se detiene gozosamente Galdós, por encontrar en ella una especie de cómico intermedio con qué aliviar las incidencias de una trama no cómica. El tan comentado folletinismo de Galdós -bien perceptible en las dos primeras series de Episodios- es, en cualquier caso, de la mejor ley, y está hecho de intuición y estudio, enderezado a conseguir la máxima atención del lector mediante un inteligente manejo de tensiones y treguas, de contrastes $\mathrm{y}$ de sorpresas.

Pero con esto nos hemos apartado del punto que ahora ocupaba nuestra atención, y que no es otro que el del relativo parentesco existente entre ciertas caricaturas galdosianas y las que fueron frecuentes entre los escritores costumbristas, como Mesonero Romanos y aun Larra. De las caricaturas de éste - con muy clara ascendencia quevedesca - algo he dicho en otra parte. ${ }^{13}$ Antes de insistir brevemente en ellas, me interesa recordar cómo Galdós se inspiró, evidentemente, en un muy conocido y admirable artículo de Fígaro a la hora de componer determinados personajes y situaciones. Efectivamente, en el capítulo III de El amigo Manso (1882) hay, en mi opinión, un claro recuerdo de El castellano viejo, en lo que se refiere a la descripción de una grotesca comida familiar. Aun siendo sobradamente conocido el artículo de Larra, transcribo algunos pasajes para que la confrontación con los parecidos del texto galdosiano resulte más clara. Sobra advertir que la coincidencia está más en el tono que en el detalle.

\footnotetext{
${ }^{12} I d$., pág. $166 b$.

${ }^{13}$ Vid. mi artículo Escritores quevedescos del siglo XIX en Barroco y Romanticismo, Universidad de Murcia, 1950.
} 


\section{LARRA}

A todo esto, el niño que a la izquierda tenía, hacía saltar las aceitunas a un plato de magras con tomate, y una vino a parar a uno de mis ojos, que no volvió a ver claro en todo el día, y el señor gordo de mi derecha había tenido la precaución de ir dejando en el mantel, al lado de mi pan, los huesos de las suyas y los de las aves que había roído.

Una criada toda azorada retira el capón en el plato de su salsa; al pasar sobre mí hace una pequeña inclinación, y una lluvia maléfica de grasa desciende, como el rocío sobre los prados, a dejar eternas huellas en mi pantalón color de perla.

\section{GALDÓS}

Distraído yo en estas cosas, no advertía que una de las niñas, sentada junto a mí, metía la mano en mi plato y cogía lo que encontraba. Después me pasaba la mano por la cara, llamándome tiíto bonito, y el chiquitín tiraba la servilleta en mitad de una gran fuente con salsa, y luego la arrojaba húmeda sobre la alfombra. La otra niña pedía con atroces gritos todo aquello que en el momento no estaba en la mesa.

Una chuleta empapada en tomate volaba hasta caer sobre la blanca pechera de la camisa del papá. ${ }^{14}$

Al tipo de castellano viejo alude Galdós en Lo prohibido (1885), en el capítulo VI de la 2. ${ }^{a}$ parte, al escribir a propósito de Medina, el marido de María Juana: «En su persona sabía María Juana convertir en letra muerta las teorías de castellano viejo preconizadas por su marido»..$^{15}$

Y en mi opinión, Galdós volvió a acordarse del mismo tipo inmortalizado por Larra en El abuelo (1897), en cuya Jornada II se describe así al Alcalde de Jerusa, por contraste con su mujer:

La Alcaldesa, señora enjuta y menudita, que no tiene en aquel momento más preocupación que parecer fina, y este sin guiar estado de su espíritu, con la tirantez consiguiente, se revela en todos sus actos, en sus palabras melosas y hasta en los mohines estudiados de su boca y nariz. Viste bata azul elegante, que le han enviado de Madrid. Poco después de ella entra el Alcalde, señorón macizo, sanote y jovial, que, al contrario de su mujer, pone todo su empeño en parecer muy bruto, dejando al descubierto, desnudo de toda retórica, su natural llano y la tosca armazón de su ser moral. Entiende que los hombres deben ser claros, cada cual mostrándose, cual Dios le ha hecho. ${ }^{16}$

Finalmente, y antes de abandonar el tema de la relación Larra-Galdós, quiero recordar aquí una descripción del primero, que es, posiblemente, la más quevedesca

\footnotetext{
${ }^{14}$ Galdós, O. C., ed. cit., tomo IV, págs. 1.187-1.188.

${ }^{15} I d$., tomo IV, pág. $1.822 b$.

${ }^{16} I d$., tomo VI, pág. $31 b$.
} 
y esperpéntica que salió de su pluma. Pertenece al conocido artículo ¿Entre qué gentes estamos?:

Dejó mi criado la señal que le pidieron, y dos horas después ya estaba en la puerta de mi casa un birlocho pardo con varias capas de polvo de todos los días y calidades, el cual no le quitaba nunca porque no se viese el estado en que estaba, y aun yo tuve para mí que lo debían de sacar en los días de aire a tomar polvo para que le cubriese las macas que tendría. Que las ruedas habían rodado hasta entonces, no se podía dudar; que rodarían siempre y que no harían rodar por el suelo al que dentro fuese de aquel inseguro mueble, esa era ya otra cuestión; que el caballo había vivido hasta aquel punto, no era dudoso; que viviría dos minutos más, eso era precisamente lo que no se podía menos de dudar cada vez que tropezaba con su cuerpo, no perecedero, sino ya perecido, la curiosa visual del espectador. Cierto sonido desapacible de los muelles y del eje le hacían sonar a hierro, como si dentro llevara medio Rastro. Peor vestido que el birlocho estaba el criado que le servía, y entre la vida del caballo y la suya no se podía atravesar concienzudamente la apuesta de un solo real de vellón; por lo mal comidos, por lo estropeados, por la poca vida, en fin, del caballo y el lacayo, por la completa semejanza y armonía que en ambos entes irracionales se notaba, hubiera creído cualquiera que eran gemelos, y que no sólo habían nacido a un mismo tiempo, sino que a un mismo tiempo iban a morir. Si andaba el birlocho, era un milagro; si estaba parado, un capricho de Goya. ${ }^{17}$

El trazo hiperbólico de esta caricatura queda plenamente justificado - caso idéntico al del joven romántico de Mesonero - por el también hiperbólico tono del resto del artículo.

Sin que suponga apuntar ninguna directa inspiración o influencia, ofrece algún interés el encontrar en Galdós una caricatura semejante en cuanto a la estrecha relación existente entre un hombre y una cabalgadura. El criado y el caballo de Larra podrían ser alineados junto a Mosén Antón y el jamelgo que monta, en Juan Martín el Empecinado (1874):

El cura iba caballero en un gran jamelgo, que parecía, por su gran alzada, hecho de encargo, para que sobre la muchedumbre ecuestre y pedestre se destacase de un modo imponente la tosca y tremebunda estampa del jefe del Estado Mayor. Caballo y jinete se asemejaban en lo deforme y anguloso, y ambos parece que se identificaban el uno con el otro, formando una especie de monstruo apocalíptico. Los brazos larguísimos y negros de Mosén Antón dictando órdenes desde la altura de sus hombros; las piernas, ciñendo la estropeada silla, que echaba fuera el relleno por informes agujeros; la sotana, partida

\footnotetext{
${ }^{17}$ M. J. de Larra, Artículos de costumbres, Clás. Cast., página 286.
} 
en dos luengos faldones que agitaba el viento y que en la penumbra de la noche parecían otros dos brazos u otras dos piezas añadidas a las extremidades reales del caballero; el escueto cuello del corcel, ribeteado por desiguales crines, que le daban el aspecto de una sierra; su cabeza negra y descomunal, que, moviéndose a compás de las patas, parecía un martillo hiriendo en invisible yunque; el son metálico de las herraduras medio caídas, que iban chasqueando como piezas Próximas a desprenderse; todo esto, que no se parecía a cosa ninguna vista por mí, se ha quedado hasta hoy fijamente grabado en mi memoria. ${ }^{18}$

Cabe advertir en esta descripción el tan frecuente oscilar galdosiano entre el dato realista — «la estropeada silla, que echaba fuera el relleno por informes agujeros»y la desmesura caricaturesca - «caballo y jinete se asemejaban en lo deforme y anguloso, y ambos parece que se identificaban el uno con el otro, formando una especie de monstruo apocalíptico».

Tanto en el retrato de Mosén Antón como en el de D. Felicísimo o en el de D. ${ }^{a}$ María Salomé, el efecto caricaturesco radica, en cierto modo, en la adscripción a los personajes retratados de un especial marco configurador, que es como su prolongación o complemento, dada la especial simbiosis que Galdós establece entre la momificada dama y sus trapos, o el fosilizado avaro y su ruinosa casa, o el esperpéntico cura y su atroz caballo.

En cierto modo, este procedimiento caricaturesco enlaza con el que pudiéramos llamar de insistencia en un rasgo o en un motivo, bastante frecuente en Dickens. Recuérdese la siguiente descripción de David Copperfield:

La recién llegada era la señorita Murdstone, mujer de aspecto sombrío y pelinegro como su hermano, al que se parecía muchísimo en la cara y en la voz; tenía unas cejas muy tupidas que casi se tocaban con su ancha nariz, como si, imposibilitada por los pecados de su sexo de llevar patillas, encontrase la compensación en las cejas. Venía acompañada de dos severas maletas negras, de material rígido, con sus iniciales dibujadas con clavos de latón en las tapas. Para pagar al cochero el importe del viaje sacó el dinero de un portamonedas de metal duro y volvió a meter aquél en un bolso que colgaba de su brazo con una pesada cadena, igual que si lo metiese en una mazmorra, y luego cerró el bolso como si le pegase un mordisco. Hasta entonces no había tenido yo ocasión de ver a una dama tan completamente metálica como la señorita Murdstone. ${ }^{19}$

Lo negro y lo duro - aunados en lo metálico - son los rasgos que cruzan de uno a otro extremo esta caricatura, próxima a alguna de Galdós en su no excesiva desrea-

\footnotetext{
${ }^{18}$ Galdós, O. C., ed. cit., tomo I, págs. 968-969.

${ }^{19}$ Dickens, O.C., ed. cit., tomo IV, pág. 47.
} 
lización, es decir, en su sustentarse en elementos reales, manejados, sin embargo, de una forma tal que equivale al ya comentado proceso de cosificación, de metalización aquí, dado el burlesco cruce de límites entre ser humano, maletas, monedero y bolso, todo ello duro, negro y metálico, agrupado en un tremendo e inhumano bloque.

Parecido al retrato de la señorita Murdstone es el de Pancks, en el capítulo XIII del libro I de La pequeña Dorrit:

Vestía aquel hombre de negro y de gris hierro oxidado; sus ojos eran dos abalorios de azabache; una barbilla negra, estropajosa; cabellos negros duros que le brotaban de la cabeza como puntas de tenedores o de horquillas de pelo, y un cutis que era muy sucio por naturaleza o muy sucio porque lo ensuciaban, o una mezcla de obra de la naturaleza y del arte. Sus manos eran sucias; sus uñas, rotas, sucias; daba la impresión de que anduviese manejando carbones; venía todo sudoroso, bufaba, aspiraba profundamente y soplaba lo mismo que una pequeña máquina de vapor que funciona con trabajo..$^{20}$

A una descripción como ésta se acerca algo la del clérigo Nicolás Rubín en Fortunata y Jacinta (1886-87). La insistencia en un mismo motivo y hasta algún rasgo hiperbólico próximo, facilitan el acercamiento:

Bien decía doña Lupe que, así como el primogénito se llevara todos los talentos de la familia, Nicolás se había adjudicado todos los pelos de ella. Se afeitaba hoy, y mañana tenía toda la cara negra. Recién afeitado, sus mandíbulas eran de color de pizarra. El vello le crecía en las manos y brazos como la hierba en fértil campo, y por las orejas y narices le asomaban espesos mechones. Diríase que eran las ideas, que, cansadas de la oscuridad del cerebro, se asomaban por los balcones de la nariz y de las orejas, a ver lo que pasaba en el mundo. ${ }^{21}$

Salió del cuarto con la cara muy mal lavada, y algunas partes de ella parecían no haber visto más agua que la del bautismo.22

\footnotetext{
${ }^{20} I d$., tomo VI, pág. 135 a.- Sobre la relación Dickens-Galdós, vid. Effie L. Erickson, The Influence of Charles Dickens on the novels of Benito Pérez Galdós, en Hispania, California, tomo XIX, 1936.Como el propio Erickson recuerda, ya Menéndez Pelayo había señalado esta influencia. Y otro tanto hicieron Clarín, Cejador, Andrenio, etc. L. B. Walton ha estudiado el humor en uno y otro escritor. En cuanto a Erickson señala, por ejemplo, influencias dickensianas en La Fontana de Oro, relacionando el tipo de D. Elías con los de Uriah Heep y Sampson Brass. La educación de Clara en el convento le recuerda pasajes de Oliver Twist y de David Copperfield, etc. Alguna vez las caricaturas de Dickens han sido interpretadas como la consecuencia de una prolongada visión infantil del mundo. Vid. sobre esto: Walter Allen, The English Novel, Pengum Books, Londres, 1960, págs. 163-164.

${ }^{21}$ Galdós, O.C., ed. cit., tomo V, pág. $209 a$.

${ }^{22} I d$., pág. $211 b$.
} 
Galdós completa una descripción caricaturesca no demasiado exagerada, con una hipérbole de raíz popular, de forma tal que el conjunto viene a constituir una muestra más de la comentada vacilación entre realismo y desmesura.

En el gusto galdosiano por la hipérbole, en su tendencia a la desmesura caricaturesca, hay que situar esa otra influencia antes apuntada, la de Quevedo, alineable junto a la de los articulistas de costumbres y a la de Dickens. Como en otra parte he tenido ocasión de estudiar brevemente, cabría distinguir, en el siglo XIX español, una muy clara tendencia quevedesca, rastreable en la obra de José Joaquín de Mora, Larra y Ros de Olano, entre otros escritores. ${ }^{23}$

La admiración de Galdós por Quevedo es tan temprana que lleva al escritor canario a redactar, en sus más juveniles años, una especie de sátira social titulada $U n$ viaje redondo por el Bachiller Sansón Carrasco, inspirada en El Diablo Cojuelo, de Vélez de Guevara, y en los Sueños quevedescos. ${ }^{24}$ También cabría recordar cómo en El Terror de 1824 (1877), compara Galdós la cárcel de Madrid con un Infierno cuyos demonios fueran los alguaciles, escribanos, procuradores, ordenanzas, etc.

Pero no es tanto el Quevedo de los Sueños como el del Buscón y algunas de las más conocidas poesías satíricas, el que influirá sobre ciertas descripciones caricaturescas de Galdós. En general, las páginas más populares y leídas de Quevedo en el siglo XIX - e incluso en nuestros días - fueron aquellas del Buscón, en que el autor describe la incré́ble avaricia y miseria del Dómine Cabra, y el cruel pupilaje que a su lado padecen Pablos y su amo. A este pasaje alude muy concretamente Galdós en el capítulo II de El Doctor Centeno (1883), al decir:

\begin{abstract}
Al pobre Doctor le parecía mentira que había de venir la tal sopa, y cuando llegó y tomó él la primera cucharada, pasóle lo que al héroe de Quevedo, esto es, que hubo de poner luminarias en el estómago para celebrar la entrada del primer alimento que tras de tan larga dieta entraba. Y razón había para ello, porque estaba con un triste pedazo de pan duro que había tomado por la mañana. ${ }^{25}$
\end{abstract}

El episodio del Dómine Cabra ha de suministrar a Galdós abundantes motivos de inspiración a la hora de trazar los retratos de algunos de sus personajes novelescos. En líneas generales, cabría considerar como una paráfrasis galdosiana del esperpéntico licenciado quevedesco al tacaño D. Mauro Requejo, que aparece en El 19 de marzo y el 2 de mayo (1873).

\footnotetext{
${ }^{23} \mathrm{Vid}$. el artículo citado en la nota 13.

${ }^{24}$ Vid. H. Chonon Berkowitz, Pérez Galdós, Spanish Liberal Crusader, Madison, 1948, pág. 37.

${ }^{25}$ Galdós, O.C., ed. cit., tomo IV, pág. $1.365 b$.
} 
La avaricia de este D. Mauro y la de su hermana doña Restituta es un trasunto - en versión realista - de la de Cabra. Galdós, como en el caso de María Salomé, presentada caricaturescamente a través de la fórmula decían malas lenguas, sitúa ahora a Gabriel Araceli en charla con un guarnicionero que vive en la misma calle de D. Mauro. Tal personaje desempeña el mismo papel que el chisme o maledicencia popular en el caso de la Porreño:

Dicen que cuando doña Restituta entra en la iglesia, roba los cabos de vela para alumbrarse en casa, y cuando va a la plaza, que es cada tercer día, compra una cabeza de carnero y sebo del mismo animal, en lo cual pringa la olla; con esto y legumbres van viviendo. Una vez al año van a la botillería, y allí piden dos cafés. Beben un poquito, y lo demás lo echa ella disimuladamente en un cantarillo que deja escondido bajo las faldas, el cual café traen a casa, y echándole agua, le alargan hasta ocho días. Lo mismo hacen con el chocolate. ${ }^{26}$

Evidentemente, esta avaricia es verosímil en sus rasgos, a diferencia de la hiperbólica del Dómine Cabra. Pero de ella procede, sin duda alguna, no en el detalle concreto - aunque algo debe la olla de los Requejo a la, tocada levemente de tocino, del Dómine Cabra - , sino en el trazo general, tratado aquí de manera entre realista y cómica.

Galdós completa luego esta caricatura de los Requejo con la descripción que de su casa hace ya directamente Gabriel, el narrador de la primera serie de los Episodios:

No debo pasar en silencio que en la casa de los Requejo había cierto aseo, aunque, bien considerado el problema, aquélla era la limpieza propia de todos los sitios en que no existe nada; exempli gratia: la limpieza de la mesa donde no se come, de la cocina donde no se guisa, del pasillo donde no se corre, de la sala donde no entran visitas, la diafanidad del vaso donde no entra más que agua.

Allí no había perro ni gato, ni animal alguno, si se exceptúan los ratones, para cuya persecución don Mauro tenía un gato de hierro, es decir, una ratonera. Los infelices que caían en ella eran tan flacos que bien se conocía que estaban alimentados con perfume. ${ }^{27}$

Tan desnuda vivienda recuerda algo la del escudero a quien Lázaro sirve en Toledo, en la que también el aseo es equivalente de no existencias, pobreza allí y no

\footnotetext{
${ }^{26} I d$., tomo I, pág. $415 a$.

${ }^{27} I d$., pág. $417 b$.
} 
avaricia. Pero más próximo que al aposento toledano está al segoviano del dómine quevedesco:

Aun arañas no había en él; conjuraba los ratones, de miedo que no le royesen algunos mendrugos que guardaba.

La «milagrosa» sotana del Dómine Cabra, entre negra, azul y «cuero de rana», está al fondo de algunas desorbitadas caricaturas galdosianas como motivo sugeridor e irradiador. En El Grande Oriente (1876), la descripción de D. Patricio Sarmiento ofrece algún trazo tal vez inspirado en la dicha tornasolada y cambiante sotana del esperpento quevedesco:

Sesenta años muy cumplidos; alta y no muy gallarda estatura; ojos grandes y vivos; morena y arrugada tez, de color puchero alcorniano y con más dobleces que pellejo de fuelle, pelo blanco y fuerte, con rizados copetes en ambas sienes, uno de los cuales servía para sostener la pluma de escribir sobre la oreja izquierda; boca sonriente, hendida, a lo Voltaire, con más pliegues que dientes y menos dientes que palabras; barba rapada de semana en semana, monda o peluda, según que era lunes o sábado; quijada tan huesuda y cortante, que habría servido para matar filisteos y que tenía por compañero y vecino a un corbatín negro, durísimo y rancio, donde se encajaba aquélla como la flor en el pedúnculo; un gorrete, de quien no se podía decir que fue encarnado, si bien conservaba históricos vestigios de este color, la cual prenda no se separaba jamás de la cúspide capital del maestro; luenga casaca castaña, aunque algunos la creyeron nuez por lo descolorida y arrugada; chaleco de provocativo color amarillo, con ramos que convidaban a recrear la vista en él, como en un ameno jardín; pantalones ceñidos, en cuyo término comenzaba el imperio de las medias negras, que se perdían en la lontananza oscura de unos zapatos con más golfos y promontorios que puntadas y más puntadas que lustre ${ }^{28}$ manos velludas, nervudas y flacas, que ora empuñaban crueles disciplinas, ora la atildada pluma de finos gavilanes. ${ }^{29}$

La descripción del miserable atuendo de D. ${ }^{a}$ Cándida, en el capítulo V de $E l$ amigo Manso, debe también algo, en sus rasgos hiperbólicos, a la del dómine quevedesco con su cambiante sotana:

\footnotetext{
${ }^{28}$ Un rasgo caricaturesco semejante se encuentra en la descripción de D. Ventura Miedes, en el cap. III de Narváez (1902): «Era don Ventura Miedes de alta estatura, que rara vez se veía derecha, sin ningún aire ni garbo; vestía en invierno y verano un cumplido levitón, que le hacía más enjuto, y en sus andares iba siempre tan desaplomado como si fuera movido del viento más que de su propia voluntad. Sus pies, grandísimos, calzaba con zapatos de paño, en que se marcaban tales protuberancias que parecían dos sacos negros llenos de avellanas y nueces» (Galdós, $O$. C., ed. cit., tomo II, pág. 1.467).

${ }^{29}$ Galdós, $O$. C., ed. cit., tomo I, pág. $1.145 a$.
} 
Prefería guiñapos de un viso elegante a una falda nueva de percal o mantón de lana. Tenía un vestido de color de pasa de Corinto, que lo menos databa de los tiempos de la Vicalvarada, y que, con las transformaciones y el uso, se había vuelto de un color así como de caoba, con ciertos tornasoles, vetas o ráfagas que le daban el mérito de una tela riquísima y milagrosa.

Usaba un tupido velo que a la luz solar ofrecía todos los cambiantes del iris, por efecto de los corpúsculos del polvo que se habían agarrado a las urdimbres. En la sombra parecía una masa de telarañas que velaban su frente, como si la cabeza anticuada de la señora hubiera estado expuesta a la soledad y abandono de un desván durante medio siglo. ${ }^{30}$

La ascendencia quevedesca es tan evidente, que lleva a Galdós a emplear el mismo adjetivo que en el Buscón encontramos referido a la sotana del Dómine Cabra, milagrosa, aplicado aquí a la tornasolada tela del vestido de D. Cándida. Como en la descripción de la casaca de D. Patricio Sarmiento, Galdós recurre a la comparación frutal, allí castaña y nuez, aquí pasa de Corinto, como indicio no sólo de color, sino de arrugamiento y vejez.

Recuérdese asimismo al sacerdote D. Juan Casado de Ángel Guerra (1890-91), del que se dice:

Vestía balandrán de aguadera, tornasolado por el constante servicio a la intemperie. ${ }^{31}$

Los ojos «avecinados en el cogote» del Dómine Cabra reaparecen en la descripción galdosiana de Urrea, en el capítulo XIX de Vergara (1899):

Era el arriero jefe cincuentón, de mediana estatura, tan chupado de rostro que los carrillos se le juntaban por dentro de la boca, formando al exterior dos cavernas velludas. ${ }^{32}$ Los

${ }^{30} I d$., tomo IV, pág. 1.178 .

${ }^{31} I d$., tomo V, pág. $1.537 b$.

${ }^{32}$ Este trazo de las mejillas sumidas, presentado hiperbólicamente, se encuentra en algunas otras descripciones de Galdós, v. gr., la de D. Juan Manuel Nones en Tormento (1884): «Era delgado y enjuto, como la fruta del algarrobo; la cara tan reseca y los carrillos tan vacíos, que cuando chupaba un cigarro creeríase que los flácidos labios se le metían hasta la laringe» (Galdós, O. C., ed. cit., tomo IV, pág. 1.503b). Resulta curioso comprobar la presencia de algunas caricaturas dickensianas caracterizadas por el mismo rasgo. Así, en el cap. III del Pickwick (1836) -recuérdese que Galdós tradujo esta obra en 1865- se dice del llamado Jaime el Triste: «Y las mandíbulas tan largas y descarnadas que cualquier observador hubiera supuesto que, por un momento, chupábase hacia adentro la carne de su rostro, merced a una contracción de los músculos, si su boca semiabierta y su expresión inmóvil no hubiera denotado que era aquélla su apariencia habitual» (Dickens, O.C., ed. cit., tomo I, pág. 29b). Y en Nuestro común amigo (1864-1865), en el cap. II del libro I y en la descripción de Twemlow se lee: «Hombre cortés, muy sensible al viento del Este, con cuello y corbata de modelo antiquísimo, mejillas 
ojos se le metían hasta el cogote, sin que de ello resultara aspecto de fiereza, sino más bien como de anacoreta, o como las malas imágenes que representan a los benditísimos padres del yermo. ${ }^{33}$

Nuevamente he de señalar otra curiosa coincidencia con Dickens. Éste, en el capítulo XXXV de Bernabé Rudge, describe así a Gashford:

Gashford, el secretario, era más alto, de formas angulosas, alto de hombros, huesudo y desgarbado. Sus ropas, a imitación de su superior, eran modestas y graves en extremo; sus ademanes, formales y contenidos. Tenía este caballero unas abultadas cejas, manos, pies y orejas grandes, y un par de ojos que parecían haber efectuado una ilógica retirada hacia el fondo de su cabeza, abriendo por sí solos una cueva donde ocultarse..$^{34}$

Este caso resulta especialmente expresivo en cuanto a la doble influencia Quevedo-Dickens - convergente, coincidente aquí- en las descripciones caricaturescas de Galdós. Con esto no quiero decir que tal caricatura de Galdós proceda de tal otra de Dickens. No, sólo quiero apuntar semejanzas, aproximaciones elocuentes y reveladoras de una tonalidad común, fácil de explicarse si tenemos en cuenta la admiración del novelista español por el creador de Pickwick y también, claro es, por el del Dómine Cabra.

Esta creación de Quevedo suministró a bastantes escritores del XIX, entre ellos Galdós, tópicos caricaturescos, extraídos no sólo del retrato físico del miserable pupilero, sino también de todo lo que a él atañe en el breve pero extraordinario cuadro del Buscón.

Así, parece evidente que la grotesca descripción, en el capítulo XXVI de $L a$ Fontana de Oro, de una comida en casa de las Porreño, procede de aquella en que Quevedo reseña el increíble yantar de Cabra y sus pupilos: «Trajeron caldo en unas escudillas de madera, tan claro, que en comer en una de ellas peligrara Narciso más que en la fuente. Noté con la ansia que los macilentos dedos se echaban a nado tras un garbanzo huérfano y solo que estaba en el suelo». «Venía un nabo aventurero a vueltas de la carne, y dijo el maestro: «¿Nabos hay? No hay para mí perdiz que se le iguale: coman; que me huelgo de vellos comer». Repartió a cada uno tan poco carnero, que en lo que se les pegó a las uñas y se les quedó entre los dientes pienso que se consumió todo, dejando descomulgadas las tripas de participantes». Véase ahora la descripción galdosiana:

\footnotetext{
chupadas, como si años atrás hubiese realizado un gran esfuerzo para sumirse dentro de sí mismo y hubiese llegado hasta ese punto sin pasar más adelante» (Ed. cit., tomo V, pág. 733b).

${ }^{33}$ Galdós, O.C., ed. cit., tomo II, pág. $1.012 a$.

${ }^{34}$ Dickens, $O . C$., ed. cit., tomo V, pág. 910 .
} 
Sirvióse primero una sopa que, por lo flaca y aguada, parecía de Seminario; después siguió un macilento cocido, del cual tocaron a Lázaro hasta tres docenas de garbanzos, una hoja de col y media patata; después se repartieron unas seis onzas de carne, que, en honor de la verdad, no era tan mala como escasa, y, por último, unas uvas tan arrugadas y amarillas que era fácil creer en la existencia de un estrecho parentesco entre aquellas nobles frutas y la piel del rostro de Salomé..$^{35}$

Aunque Galdós sitúa la descripción de una comida mísera en un plano realista y evita en lo posible el rasgo excesivamente hiperbólico — «unas seis onzas de carne, que, en honor de la verdad, no era tan mala como escasa»-, no pudo dejar de incurrir en él para reforzar, con la nota de las uvas arrugadas y amarillas, la descripción de la momificada Salomé. Al fondo de la estampa galdosiana está la ya citada de Quevedo, como es fácil percibir a poco que se cotejen una y otra. Aparte de los concretos detalles de la comida - aguado caldo en ambas; escasos garbanzos en Galdós, reducidos a uno sólo en Quevedo; un nabo aventurero en éste, una hoja de col y media patata en La Fontana, etc.- , ofrece interés comprobar cómo el recuerdo de la descripción quevedesca pesó de tan intensa forma en la de Galdós, que incluso afectó a la sintaxis y al vocabulario. Si sustituimos la frase «una sopa que, por lo flaca y aguada, parecía de Seminario» por «una sopa, tan flaca y aguada, que parecía de Seminario», tendremos una construcción próxima a caldo «tan claro que en comer en una de ellas peligrara Narciso». Los macilentos dedos del Dómine se han trocado aquí en el macilento cocido de las Porreño. Parece evidente que, aunque Galdós no tuviera delante la caricatura quevedesca, algo de ella — tan conocidavivía en su recuerdo; lo suficiente para organizar un exiguo menú y para describirlo en términos próximos a los empleados por Quevedo. Recuérdense también las expresiones con que Cabra pondera la abundancia de tal comida o la sobriedad de la cena. De la primera dice: «Y váyanse hasta las dos a hacer ejercicio, no les haga mal lo que han comido». Y del aún más escaso yantar nocturno: «Es cosa muy saludable y provechosa - decía - cenar poco para tener el estómago desocupado; y citaba una retahíla de médicos infernales».

En La Fontana de Oro, a continuación del pasaje transcrito, se lee:

Terminó con esto el festín, durante el cual reinó en el comedor un silencio de refectorio, excepto cuando Elías dijo que tanta esplendidez le parecía dispendiosa, y elogió la sobriedad como fundamento de todas las virtudes. ${ }^{36}$

\footnotetext{
${ }^{35}$ Galdós, O. C., ed. cit., tomo IV, pág. $110 b$.

${ }^{36} I d$., pág. $110 b$.
} 
Hasta tal punto tenía presente Galdós en su recuerdo la descripción quevedesca, que en la misma novela, y en su capítulo $\mathrm{V}$, al describir el sombrío ambiente del convento en que fue educada Clara, apunta:

Las niñas se levantaban muy temprano y rezaban; almorzaban unas sopas de ajo, en que solía nadar tal cual garbanzo de la víspera. ${ }^{37}$

Sin necesidad de buscar concretos antecedentes quevedescos, cabe asegurar que todo lector atento de Galdós percibirá el indeclinable gusto del novelista por las hipérboles. En algún caso éstas son manejadas - al igual que en ejemplos próximos de Quevedo- para ponderar una increíble vejez. ¿Quién no recuerda aquel soneto quevedesco - de estructura semejante al de la nariz, en lo que a sucesión de hipérboles se refiere - que comienza:

Antes que el repelón, eso fue antaño.

Ras con ras de Caín; o por lo menos

la quijada que cuentan los morenos

y ella, fueran quijadas en un año?

Galdós, en el capítulo III de El Doctor Centeno, al describir la vejez de D. ${ }^{a}$ Isabel Godoy, procede también hiperbólicamente, si bien, curándose en salud, filtra la caricatura a través de su fórmula habitual: la usada al describir la avaricia de los Requejo o la momificación de Salomé Porreño:

Su edad, ¿quién la sabe? Decía Alejandro que su títa era contemporánea del protoplasma, para expresar así la más larga fecha que cabe imaginar. Puede decirse, en corroboración de esto, que la señora era una de esas naturalezas escogidas que han celebrado tregua $o$ armisticios con el tiempo, y que tienen el don de prolongarse y conservarse momificadas en vida para dar qué decir y qué envidiar a dos o tres generaciones. ${ }^{38}$

Otras veces la hipérbole funciona simplemente como el subrayado grotesco de la fealdad física, propia de algún personaje galdosiano. Es obvio que la caricatura se realiza, predominantemente, con este sentido. Por eso contrastan en la obra cervantina, frente a la galería de mujeres, prodigios todas de belleza, que se encuentran tanto en las Novelas Ejemplares, como en el Quijote, etc., las descripciones caricaturescas

\footnotetext{
${ }^{37}$ Id., pág. $37 a$.

${ }^{38}$ Galdós, $O$. C., ed. cit., tomo IV, pág. $1.350 b$.
} 
de Maritornes, y muy especialmente de una peregrina que, cerca de Talavera, conocen los protagonistas del Persiles:

El rostro daba en rostro, porque la vista de un lince no alcanzaba a verle las narices, porque no las tenía sino tan chatas y llanas que con unas pinzas no le podían asir una brizna de ellas; los ojos les hacían sombra, porque más salían fuera de la cara que ella.

En el arte barroco, tanto vale el encarecimiento de la más increíble belleza como - en el extremo contrario - el de la más desaforada fealdad. Uno y otro se sostienen y complementan mágicamente dentro del irreal recinto de una expresión literaria que no refleja el mundo tal cual es, sino el mundo que el artista crea y que el lector desea. La mentira - las cítaras de pluma o los zapatos como tumbas de filisteos - es un valor estético, y hay que contar con ella, ya se maneje como metáfora, hipérbole o total estructura literaria (Tema del engaño, mentir amoroso de D. Juan, gusto por el disfraz - doncellas vestidas de hombres, criados de amos - en la novela y en el teatro seiscentistas, etc.).

Las hipérboles galdosianas se mueven dentro de un mundo novelesco con apetencias realistas. De ahí su especial configuración. Aun así, véase cómo el novelista describe la grotesca fealdad de la hermana del clérigo Polo en la ya citada obra $E l$ Doctor Centeno:

Era lo que, en toda la amplitud de la palabra, se llama una mujer fea. Su cara se salía ya de los términos de la estética, y era verdaderamente una cara ilícita, esto es, que quedaba debajo del fuero del poder judicial. Debía, por consiguiente, recaer sobre ella la prohibición de mostrarse en público. Así lo conocía la dueña de aquel monumento azteca, y ni tenía en su habitación espejos que se le reprodujeran, ni salía más que para ir a la iglesia, o a visitar amigas de confianza. ${ }^{39}$

No hay ningún dato físico - fuera del obtenible, por referencia, de la comparación monumento azteca - a diferencia de lo que ocurre en la semblanza de doña Petra (llamada D. a Desdémona) en el capítulo I de la parte IV de Fortunata y Jacinta:

Su mujer competía en elegancia con una boya de las que están ancladas en el mar para amarrar de ellas los barcos. Su paso era difícil, lento y pesado, y cuando se sentaba, no había medio de que se levantara sin ayuda. Su cara redonda semejaba farol de alcaldía o Casa de Socorro, porque era roja y parecía tener una luz por dentro: de tal modo brillaba. ${ }^{40}$

\footnotetext{
${ }^{39} I d$., pág. $1.317 a$.

${ }^{40} I d$., tomo V, pág. $442 b$.
} 
En una línea semejante, en lo que a cómica ponderación de una corpulenta mujer se refiere, cabría recordar, en el capítulo I de Miau (1888), la descripción de la señora de Mendizábal:

La señora de Mendizábal era de tal corpulencia que, cuando estaba dentro del escritorio, parecía que había entrado en él una vaca, acomodando los cuartos traseros en el banquillo y ocupando todo el espacio restante con el desmedido volumen de sus carnes delanteras. ${ }^{41}$

Obsérvese el lenguaje empleado en una y otra descripción: «semejaba farol», «parecía que había entrado en él una vaca». Falta, como en otros casos, la rotundidad de la equiparación barroca, tan repetida y característica del arte caricaturesco de Quevedo.

Sin embargo, también Galdós, en alguna ocasión, suprime el término atenuador y llega a la total equiparación. Todo es cuestión de grado. Si le sonaba mejor al novelista «semejaba farol» que «era...», no hay, en cambio, dificultad en el trueque moderadamente hiperbólico que experimentan algunos rasgos de una fisonomía femenina, los de la Jusepa de Ángel Guerra (capítulo I de la 3. parte):

La Naturaleza había compuesto en ella uno de sus más esmerados ejemplares de antídotos contra el amor, dándole una patata por nariz, ojos de pulga, boca de serón, color de barro crudo, cabellos ralos y desiguales y no muy blancos dientes. ${ }^{42}$

Los rasgos hiperbólicos no son, en este caso, lo suficientemente exagerados como para romper la textura realista del contexto. Y, además, hay que tener en cuenta que por moderación realista o, simplemente, por falta de imaginación caricaturesca, Galdós cierra su semblanza con unos rasgos plenamente realistas.

La hipérbole montada sobre el abultamiento de un único rasgo fisiognómico caso del soneto a una nariz, de Quevedo- puede quedar ejemplificada, en Galdós, con el siguiente pasaje del capítulo VIII de España sin rey (1907-08):

Lo culminante del rostro terrible de don Hilarión era un bigote tan grande, que con él podrían hacerse hasta una docena de regulares proporciones para hombres bien barbados y bigotudos. Más que bigotes, eran dos cortinas que arrancaban del labio superior, y con pelo de la cara hábilmente dispuesto, se prolongaban hasta los hombros. El color negro, retinto, abetunado, hacía más terroríficas las magníficas excrecencias capilares, obra de los años y de un cultivo esmeradísimo. ${ }^{43}$

\footnotetext{
${ }^{41} I d$., pág. $552 b$.

${ }^{42} I d$., pág. 1.426b.

${ }^{43} I d$., tomo III, pág. $785 b$.
} 
Ésta, como otras muchas caricaturas de Galdós, presenta ese paradojal rasgo de la hipérbole refrenada o moderada. Se trata, pues, de una exageración con sordina, la impuesta por el sustrato burgués de que se alimenta el novelar galdosiano. Entre el vuelo sin lastre de la fantasía barroca y el apego a la tierra, encarnado en el dato concreto del naturalismo, Galdós, como Dickens, e incluso como Balzac, se mantiene literariamente en un ámbito intermedio, hecho de concreción realista y de pirueta imaginativa.

Algún ejemplo cabría recordar en la novelística galdosiana de caricatura conseguida sin abultamiento o deformación de un detalle propio del físico o del atuendo.

D. José M. ${ }^{a}$ Malespina, en Trafalgar (1873), es un personaje cuya comicidad -cuyo perfil caricaturesco- reside en su gusto por las mentiras, tan desenfrenadas éstas que hacen pensar en seguida en el tipo tradicional del Barón Münchhausen o de la Castaña. Indudablemente, los fantásticos embustes de este bien conocido personaje están al fondo de los ideados por Malespina. Bastaría recordar aquel pasaje del capítulo VII, en que el gran mentiroso relata algunas de sus proezas militares:

Pero yo, que veía las cosas de otra manera, me estuve callandito hasta que una columna francesa vino a colocarse delante de mí, en tal disposición que mis disparos podían enfilarla de un extremo a otro. Los franceses forman la línea con gran perfección. Tomé bien la puntería con una de las piezas, dirigiendo la mira a la cabeza del primer soldado... ¿Comprende usted?... Como la línea era tan perfecta, disparé y, ¡zas!, la bala se llevó ciento cuarenta y dos cabezas, y no cayeron más porque el extremo de la línea se movió un poco ${ }^{44}$.

Una nueva versión, moderada, de este tipo tradicional del mentiroso a lo Münchhausen aparece en La Corte de Carlos IV (1873), en la figura de un marqués diplomático que va a casa de la González y que, según se encarga de apuntar el propio narrador, Gabriel Araceli, «recordaba a cierto mentiroso que conocí en Cádiz, llamado don José María Malespina. Ambos eran portentos de vanidad; pero el de Cádiz mentía desvergonzadamente y sin atadero». ${ }^{45}$

Pero no son éstas las caricaturas más abundantes en Galdós, ni las que más nos importan ahora. Son las otras - las ya transcritas y las que a ellas se acercan - las que ofrecen un cierto interés, al plantear el problema literario, tantas veces citado, de cómo es posible la convivencia de realismo novelesco y desmesura caricaturesca en unas mismas obras, sin que se rompa su ritmo o tonalidad.

\footnotetext{
${ }^{44} I d$., tomo I, pág. $226 a$.

${ }^{45} I d$., pág. 303.
} 
En Dickens el problema no es tal, o, por lo menos, no ofrece los mismos acusados perfiles que en el caso de Galdós. La realidad que el novelista victoriano ofrece es una realidad tan sui generis, tan inequívocamente novelesca como para admitir, sin violencia ni esfuerzo, todas las sorpresas, todos los trucos folletinescos que la más acalorada fantasía puede imaginar. Y también, claro es, todas las más regocijantes y desbordadas caricaturas.

Hay que tener en cuenta, además, que Dickens trabajó alguna vez en verdadera colaboración con dibujantes de caricaturas. El Pickwick nació, en cierto modo, de una idea del dibujante Seymour al proponer a los editores Chapman y Hall que Dickens escribiera un texto para unos dibujos suyos. André Maurois cuenta así ese episodio:

Cuando empezó Pickwick no tenía la menor idea de cómo proseguiría esta obra, y menos aún de cómo la concluiría. No se había trazado ningún plan; concebía personajes, los echaba al mundo y marchaba tras ellos.

El primer episodio no alcanzó gran éxito; ya publicado el segundo, el dibujante, que estaba algo loco, se suicidó, y como quiera que la venta no fuese mucha, los editores, por un momento, pensaron en suspender la publicación. Luego se encontró otro dibujante, Phiz, y decidieron continuarla. ${ }^{46}$

Y el mismo Maurois comenta:

No es una simple casualidad el debut de Dickens como colaborador de un caricaturista; Dickens fue toda su vida ilustrado por caricaturistas que él guió y con los que colaboró complacido. Empleo la palabra caricatura sin la menor intención de crítica. La caricatura es un arte. Hogarth, Gavarni, Forain, son unos grandes artistas. El cometido del arte es el de darnos una imagen inteligible de la naturaleza; ahora bien, la caricatura es una constante deformación traída por un espíritu de hombre a la naturaleza. Representa ella, pues, en el primer punto, un estilo, a condición de que sea espontánea y que exista una cierta unidad en la deformación. Contemplad varios personajes de Gavarni. Reconoceréis una deformación típicamente Gavarni, totalmente distinta de una deformación de Forain, y por esa son uno y otro unos artistas. De igual manera existe una deformación característicamente dickensiana. Y es perfectamente legítimo que así sea. Y es, sin duda, justamente porque los personajes de Dickens son estilizados, que han pasado como tipos en la tradición de un país.

\footnotetext{
${ }^{46}$ A. Maurois, Dickens, trad. de R. Vázquez Zamora, Ed. Apolo, Barcelona, 1952, págs. 36-37.
} 
De lo que sí cabe lamentarse, y se lamenta el lector moderno, es que tal caricatura, esa simplificación de los trazos, nos impida creer, según sería nuestro deseo, en los personajes de sus libros. ${ }^{47}$

Algo parecido, aunque en otro grado, ocurre frente a ciertas descripciones caricaturescas de Galdós, más perturbadoras aún, si cabe, que las de Dickens, porque en las obras de éste la tónica dominante participa de ese signo, en tanto que en las del novelista español los toques intensamente realistas parecen oponerse a toda idea de convivencia con los, aparentemente, irreales rasgos de una caricatura.

Si contemplamos algunas de esas encantadoramente añejas ilustraciones de Phiz, reproducidas aún en algunas ediciones modernas de las obras de Dickens, veremos cómo en bastantes de ellas conviven sin conflicto, pero con evidente contraste plástico, los convencionales seres dickensianos, esas aniñadas bellezas femeninas tipo Dorrit, con los más grotescos personajes. Las facciones no realistas — tanta es su convencional dulzura - de los personajes del primer tipo, aparecen alineadas junto a los rostros increíblemente alargados, achatados o, en suma, cómicamente desproporcionados de los personajes grotescos o malignos. Phiz dibuja a unos y a otros mezclándoles en una misma ilustración, pese a su disparidad —o precisamente por ella misma - , al igual que, en sus novelas, Dickens hace convivir a unos y a otros personajes sin detrimento de la unidad de tono y de estilo.

Éste es precisamente el efecto, transportado a lo literario, que provocan ciertas páginas de Galdós, e incluso algunas de Balzac. Perseguir en la obra de éste el sentido y frecuencia de sus descripciones caricaturescas es tarea que no cabe ni tan siquiera insinuar aquí. Únicamente, y a título de brevísima muestra, quiero recordar, por su relación con ciertas figuras dickensianas y galdosianas de avaros - entre éstas, la de Torquemada como la más famosa - , las magistrales creaciones de Balzac, inspiradas por ese tan explotado tipo literario. Aparte del padre Grandet y de Gobseck - ese Gobseck del que Vautrin dice, hiperbólicamente, en Papá Goriot, que es «un bribón, capaz de hacer fichas de dominó con los huesos de su padre»-, cabría citar a otros avaros menores, tan caricaturescamente presentados a veces como el Samanón de Ilusiones perdidas

Tratante en libros viejos en el piso bajo, ropavejero en el primero y tratante en grabados prohibidos en el segundo, Samanón era, además, prestamista. Ninguno de los personajes que aparecen en las novelas de Hoffmann, ninguno de los siniestros avaros de Walter Scott, podría ser comparado con aquel hombre creado por la naturaleza social parisiense, si es que podía llamarse hombre a Samanón. Luciano no pudo reprimir un gesto de es-

${ }^{47} I d$., págs. $152-154$. 
panto al ver a aquel ancianito seco, cuyos huesos querían perforar su piel perfectamente curtida y plagada de numerosas manchas verdes y amarillas, como un cuadro de Ticiano o de Pedro Veronés visto de cerca. Samanón tenía un ojo inmóvil y helado, y el otro vivo y reluciente. El avaro, que parecía servirse de aquel ojo muerto para hacer los descuentos y emplear el otro para vender sus grabados obscenos, llevaba una peluca, cuyos cabellos negros empezaban ya a enrojecer y bajo la cual se veían algunos pelos blancos. Su amarilla frente tenía un no sé qué de amenazador, sus mejillas estaban hundidas y sus dientes, blancos aún, permanecían al descubierto. El contraste de sus ojos y la mueca de aquella boca le daban un aspecto bastante feroz. Los pelos de su barba, duros y puntiagudos, debían pinchar como alfileres. Una levita raída, llegada ya al estado de yesca, y una corbata negra desteñida y rozada por la barba, que dejaba ver un cuello arrugado como el de un pavo, anunciaban claramente la indiferencia de aquel hombre en lo que atañía a disimular su siniestra figura.

Con relación a las descripciones de Balzac, habría que tener en cuenta la devoción del novelista por la frenología de Gall — devoción expresada a través de una de sus más conocidas criaturas novelescas, el médico Horacio Bianchon-, así como su condición de contemporáneo de Daumier, el genial dibujante satírico, creador de estampas, de cáusticos dibujos, de grabados rebosantes de intención y de vida, paradójicamente literarios en su pura condición plástica, por los temas, ambientes y, sobre todo, por la especial perspectiva desde la que todo está visto y enjuiciado. En esos admirables grabados de Daumier podríamos encontrar el mejor ejemplo o equivalente plástico de la perfecta conciliación o ajuste entre realidad y caricatura, que hemos estudiado en Galdós.

En sus novelas, las caricaturas no suponen una nota estridente, capaz de alterar una tonalidad o textura descriptiva. Por el contrario, son el refuerzo expresivo de un realismo que no se despeña en la pretensión de una plena objetividad. Las caricaturas literarias galdosianas revelan que el novelista está al lado de sus criaturas novelescas, amorosa, cálidamente, incluso cuando se burla de ellas, con el más familiar y entrañable de los acentos.

Boletín de la Biblioteca de Menéndez Pelayo, 36, 1960, págs. 331-362. Perspectivismo y contraste (De Cadalso a Pérez de Ayala), Madrid, Gredos, 1963, págs. 43-82. 